\title{
Due-Date Assignment for Wafer Fabrication Under Demand Variate Environment
}

\author{
W. L. Pearn, S. H. Chung, and C. M. Lai
}

\begin{abstract}
In the semiconductor industry, dynamic changes in demand force companies to change the product mix frequently and periodically. Assigning tight but attainable due dates is a great challenge under the circumstances that the product mix changes periodically. In this paper, we consider the due-date assignment problem for wafer fabrication and present a due-date assignment model to set manufacturing due dates satisfying the target on-timedelivery rate. The contamination model is applied to tackle the effect of that product mix varies periodically. We demonstrate the effectiveness and accuracy of the proposed model by solving a realworld example taken from a wafer fabrication shop floor in an IC manufacturing factory.
\end{abstract}

Index Terms-Contamination model, due-date assignment, flow time, product mix, wafer fabrication.

\section{INTRODUCTION}

$\mathbf{S}$ EMICONDUCTOR companies must maintain high-level customer service to gain their competitive edge. In order to quickly respond to customers' fluctuating demand, companies often make changes on the product mix frequently and periodically. Under the circumstances that the product mix changes periodically, assigning tight but attainable due dates to achieve the target on-time-delivery rate would be a great challenge. In this paper, we consider the due-date assignment problem for wafer fabrication, an extension of the problem considered by Chung et al. [1], which has many real-world applications, particularly, in the integrated circuit (IC) manufacturing industry.

Due-date assignment has always been an important research topic in production planning and control systems, which has attracted abundant research interest. Surveys on recent results of specific aspects of due-date assignment problems, such as Cheng and Gupta [2] and Gordon et al. [3], [4], confirm this continued interest. The methods of due-date assignment used in the related literature can be classified into two categories: analytical approaches and simulation approaches. The analytical approach offers an exact way that determines mean and variance of flow-time estimates and further sets due dates. Seidmann and Smith [5] studied the constant due-date assignment policy with the objective of minimizing the expected aggregate cost per job subject to restrictive assumptions on the priority discipline and the penalty functions. Cheng [6] proposed a method to assign optimal total work content (TWK) due dates. Enns [7] used dynamic flow-time forecasting to set due dates with

Manuscript received October 13, 2005; revised March 2, 2007.

The authors are with the Department of Industrial Engineering and Management, National Chiao Tung University, Hsinchu, Taiwan, R.O.C. (e-mail: wlpearn@mail.nctu.edu.tw; shchung@mail.nctu.edu.tw; chunmei.iem88g@ nctu.edu.tw).

Digital Object Identifier 10.1109/TSM.2007.895215 the objective of minimizing related costs of job shop scheduling. Li and Cheng [8] analyzed the single machine due-date determination and the resequencing problem with the objective of minimizing the maximum weighted tardiness and the cost of due-date assignment. Hopp and Roofsturgis [9] developed a due-date quoting method to achieve a target service level by determining lead times as a function of work in process and using a control chart method for adjusting the parameters in the function overtime. Ooijen and Bertrand [10] proposed a method to set the optimal due dates by considering work load, lead time-related, and tardiness-related costs. The other trend in the analytical approach is to set due dates by determining flow-time prediction errors and distribution functions [11]-[13].

For the simulation approaches, researchers examined the relative performance of various due-date assignment rules, dispatching rules, or sequencing procedures [14]-[16]. Other studies of simulation approaches are to develop effective flowtime estimation and due-date assignment policies based on the simulation studies. Weeks [17] proposed a method to assign the due date based on the expected job flow time and shop congestion information and concluded that such due dates were more attainable. Vig and Dooley [18] proposed two new flow-time estimation methods. They also evaluated relationships between several shop factors and effects on the due-date performance via a simulation study. Vig and Dooley [19] further incorporated the steady-state with dynamic flow-time estimates to develop flow-time estimation and provided a regression-based approach for setting job-shop due dates. Raghu and Rajendran [20] developed a due-date setting policy for a real-life job shop by incorporating the best performing dispatching rule which is selected by simulation. Roman and del Valle [21] presented a rule for the due-date assignment problem of reducing the tardiness and percentage of delayed jobs through a combination of the dispatching rule and assignation of due dates. Chang [22] showed that statistical analysis of a simulation model could give valuable insights into the flow-time behavior of jobs through workstations and proposed an approach to provide real-time estimates of the queueing time for the remaining operations of the jobs. For the due-date setting in queueing networks, Glassey and Seshadri [23] proposed approximations for univariate and multivariate distributions of nonnegative random variables, which can be applicable in a more general environment. Riano et al. [24] integrated an advanced planning model with a discrete event simulation model for the systems whose lead times are random variable distributions.

Due to the complexity of the wafer manufacturing process, the due-date assignment problem in semiconductor companies is more difficult to solve than the classical due-date assignment problem. A product mix that varies periodically is an even 


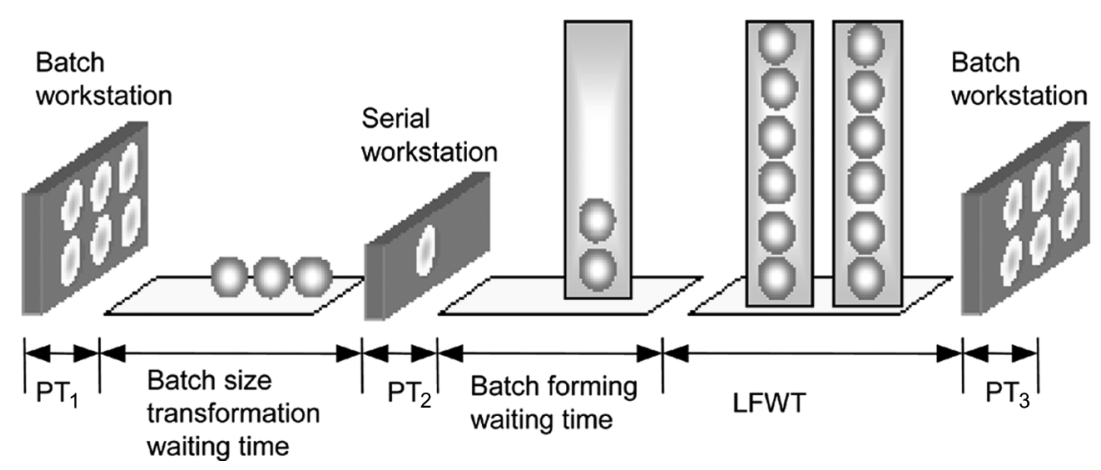

Fig. 1. Formation of flow time for lots.

more complicated problem compared to other manufacturing industries. Chung et al. [1] presented a due-date assignment model by using the simulation method and queueing theory. They also proposed a methodology of determining related parameters for flow-time control. Chung and Huang [25] developed a production flow-time estimation formulation, the blockbased cycle time (BBCT) estimation algorithm. The BBCT algorithm has distinguishable performance in estimating mean flow time where the product mix is fixed during all the time periods. Unfortunately, their models do not consider the product mix periodically changes and thus might not reflect the real situation accurately.

In this paper, we consider a more general version of a duedate assignment problem for wafer fabrication. We present a due-date assignment model that is consistent with the target on-time-delivery rate where product mix changes periodically. Flow times are first analyzed for each product type under single product mix. The contamination model is applied to tackle the effect of product mix changes in a periodical fashion. A due-date assignment model is then presented for wafer fabrication where product mix changes periodically. To illustrate the effectiveness and accuracy of the proposed model, we consider a real-world example taken from a wafer fabrication shop floor in an IC manufacturing factory located in the science-based Industrial Park in Hsinchu, Taiwan, and solve the problem on assigning due dates for orders.

This paper is organized as follows. Section II describes production system environment and system input. Section III describes the data distribution where the product mix is fixed throughout the time periods. Section IV applies contamination model to the due-date assignment model where the product mix changes periodically. Section $\mathrm{V}$ presents case studies and shows the effectiveness and accuracy of the proposed system. Some concluding remarks are made in the last section.

\section{Production System Environment And System InPut}

Wafer fabrication is a highly complex and time-consuming process. Typically, the production process has several unique characteristics. First, the process comprises several hundred steps on a single wafer. In addition, the manufacturing flow of different products may differ significantly, and the processing time required of the machines for one product may be twice as much as that required for the other products [26]. Second, some of the machines may be used for the same operation more than once as successive circuit layers are added in the production process, and this is termed re-entrant flow property. One problem caused by this property is that different layers of a wafer have to go through the same machines and to compete with other wafers for the same resources. Finally, based on the number of lots being processed simultaneously, machines are usually categorized into serial or batch types. Batch operations would cause wafer lots additional waiting time due to batch size transformation. As a result, these interrelated characteristics complicated flow-time analysis and due-date assignment for the semiconductor fabs.

Furthermore, a product mix that varies periodically makes the system more complicated. In a semiconductor fab, machines are shared by plenty of different products, resulting in a heavy loading on the precious resource. The product mix has considerable impact on production throughput, flow time, and the capability of meeting due dates. Production throughput, flow time, machine utilization, and work-in-process (WIP) inventory are highly interrelated [26], [27]. Under different product mixes, the overall performance of the manufacturing system would be different. Thus, the effect of product mix changes should be taken into consideration when assigning manufacturing due dates.

Flow time for a wafer lot flowing through the entire production process includes raw process time (PT) and waiting time (WT) [25]. PT consists of the pure processing time, loading, and unloading times. WT includes the following two parts.

1) Load factor waiting time (LFWT): The LFWT represents the time for a lot waiting for an available workstation. The load on a workstation reflects the utilization rate and influences the average waiting time of a candidate batch lot.

2) Batch factor waiting time (BFWT): The BFWT represents the time for a release batch flowing through the whole process without considering PT and LFWT. BFWT comprises the following two parts.

a) Batch forming waiting time: The waiting time is caused by gathering lots to form a batch.

b) Batch size transformation waiting time: The waiting time is caused from transferring lots from an upstream batch workstation to a downstream workstation when the downstream workstation processes a smaller batch size. A temporary peak load thus occurs at the downstream workstation.

The formation of the flow time for lots is depicted in Fig. 1. PT is a known constant, while WT is the variable that needs to 
be estimated. Due to the complexity of WT, a simulation-based WT distribution is used to estimate WT in this study.

A modern fab requires a very high capital investment, usually a billion dollars or more [28]. Generally, the wafer stepper machines are the most expensive machines in wafer fabrications and are treated as the bottleneck. The tremendous amount of investment makes the manufacturers put emphasis on fully utilizing the bottleneck machine. On the other hand, if the utilization rate of bottleneck machine is set too high, the system may be unstable because of unforeseen disruptions. Therefore, the strategy is to keep the utilization rate of bottleneck in a given range with the consideration of maximizing the utilization of bottleneck while keeping the production system stable.

The batch size of wafer release is set to be six lots. Such a setting could raise the throughput rate of many workstations, which have a maximum batch size of six lots.

Wafer lots are released under a CONWIP (CONstant Work In Process) release policy [29]. By adopting the CONWIP policy, the WIP is kept reasonably constant. As such, the flow-time distribution should also be reasonably stationary. Based on CONWIP release policy, wafer lots are released into the plant only when WIP level is lower than the planned WIP level $L$. Once the WIP level is lower than $L$, six lots (the release batch size) of a product type which has the largest accumulated unreleased quantity is released into the plant. The calculation of "accumulated unreleased quantity" is based on the planned daily release amount. When the product is assigned to release, six lots are deducted from the corresponding unreleased quantity. On the other hand, if there are remaining quantities not released to the plant, the unreleased quantities will be accumulated to the next day.

\section{Due-Date Assignment for Single Product Mix}

We begin by considering the due-date assignment problem for product mix that is fixed throughout the time periods. Waiting time (WT) of each product type is first modeled by gamma distribution. Due dates can then be set based on release date, PT, and WT fitted distribution.

\section{A. WT Distribution Fitting for Single Product Mix}

The gamma distribution is a nonnegative domain and rightskewed probability distribution. The gamma distribution is frequently used as the probability model for waiting times. For instance, in life testing, the waiting time until "death" is a random variable which is frequently modeled by a gamma distribution. In addition, the gamma distribution is also a good model for many nonnegative random variables of the continuous type, because the two parameters $\alpha$ and $\beta$ provide a great deal of flexibility [30].

A random variable $X$ is said to have a gamma distribution with parameters $\alpha>0$ and $\beta>0$. The probability density function of $X$ is

$$
\phi_{X}(\alpha, \beta)= \begin{cases}\frac{x^{\alpha-1} e^{-x / \beta}}{\beta^{\alpha} \Gamma(\alpha)}, & 0 \leq x<\infty \\ 0, & \text { otherwise }\end{cases}
$$

where $\Gamma(\alpha)$ is known as the gamma function, defined by $\Gamma(\alpha)=$ $\int_{0}^{\infty} t^{\alpha-1} e^{-t} d t$. In this gamma distribution, $\mu=E(X)=\alpha \beta$ and $\sigma^{2}=V(X)=\alpha \beta^{2}$.
In the wafer fabrication process, WT of each product type is always nonnegative and skews to the right and can be modeled satisfactorily by the gamma distribution. The method of moments estimators is used for unknown parameters $\alpha$ and $\beta$. The first two moments of the gamma distribution with parameters $\alpha$ and $\beta$ are

$$
\begin{aligned}
& \mu_{1}^{\prime}=\mu=\alpha \beta \\
& \mu_{2}^{\prime}=\sigma^{2}+\mu^{2}=\alpha \beta^{2}+\alpha^{2} \beta^{2} .
\end{aligned}
$$

Equate these quantities to their corresponding sample moments. Thus

$$
\begin{aligned}
& \mu_{1}^{\prime}=\alpha \beta=m_{1}^{\prime}=\bar{x} \\
& \mu_{2}^{\prime}=\alpha \beta^{2}+\alpha^{2} \beta^{2}=m_{2}^{\prime}=\frac{1}{n} \sum_{i=1}^{n} x_{i}^{2} .
\end{aligned}
$$

From (4) and (5), we can obtain $\hat{\alpha}=\bar{x}^{2} / S^{2}$ and $\hat{\beta}=S^{2} / \bar{x}$, where the sample average $\bar{x}=\sum_{i=1}^{n} x_{i} / n$ and the sample variance $S^{2}=\sum_{i=1}^{n}\left(x_{i}-\bar{x}\right)^{2} / n$ are the estimators of $\mu$ and $\sigma^{2}$, respectively.

\section{B. Due-Date Setting}

Like firms in other industries, semiconductor companies must meet customers' fluctuating demands in order to survive. Failure to deliver products on time, even with the right quality and quantity, can result in profit penalties or loss of customers. The on-time-delivery rate is an important determinant to measure customer service. The target on-time-delivery rate is therefore chosen as our due-date performance measure. The advantage of this policy is that it combines the competitive advantage of short lead times with the requirement that target numbers of due-date promises can be met [12].

The due date of an order is assigned to the date that equals the release time of the order plus raw process time (PT) and the $\delta$-percentile waiting time, where $\delta$ is the target fraction of on-time-delivery orders. The $\delta$-percentile waiting time can be obtained by taking the inverse of the cumulative function of the fitted gamma distribution. The due date of order $d$ can then be assigned as

$$
D_{d}=r_{d}+P T_{d}+F G_{d}^{-1}(\delta)
$$

where $D_{d}$ is the due date of order $d, r_{d}$ is the release date of the latest batch of order $d, P T_{d}$ is PT of order $d$, and $F G_{d}^{-1}(\delta)$ is the inverse of the cumulative function of the fitted gamma distribution of order $d$. Fig. 2 illustrates the due-date assignment based on the target on-time-delivery rate. We note that, in many cases, it is true that PT is less than WT. However, in some other cases, PT is greater than WT due to different machine utilization rate. In our case, because utilization rates of some machines are relatively small, we thus have PT greater than WT.

Consider the following due-date assignment examples with two product types ( $\mathrm{L}$ and $\mathrm{M}$ ) being produced in the plant. PT of these two product types are known as: $120 \mathrm{~h}$ for product $\mathrm{L}$ and $145 \mathrm{~h}$ for product M. Table I displays the estimated parameters for WT fitted distributions under product mix $L: M=4: 6$ 


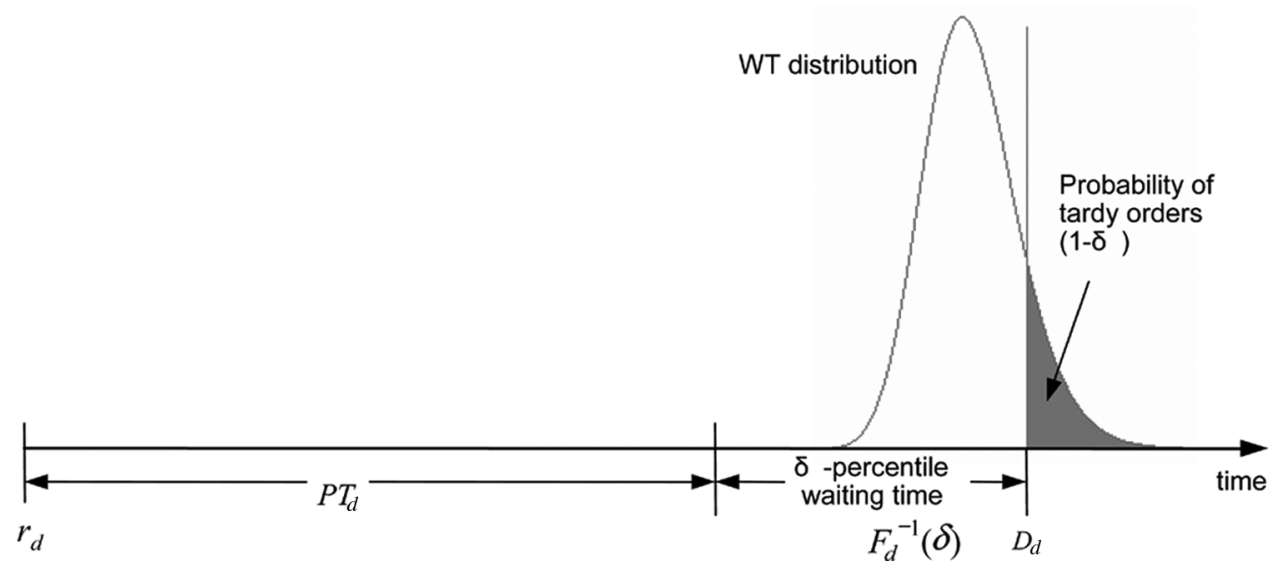

Fig. 2. Due-date determination based on target on-time-delivery rate.

TABLE I

ESTIMATED PARAMETERS FOR WT DISTRIBUTIONS

\begin{tabular}{|c|c|c|c|c|}
\hline \multirow{2}{*}{$\begin{array}{c}\text { Product mix } \\
\text { (L:M) }\end{array}$} & \multicolumn{2}{|c|}{ Product L } & \multicolumn{2}{c|}{ Product M } \\
\cline { 2 - 5 } & $\hat{\alpha}$ & $\hat{\beta}$ & $\hat{\alpha}$ & $\hat{\beta}$ \\
\hline $\operatorname{Mix}(4: 6)$ & 25.0 & 2.0 & 26.0 & 2.3 \\
\hline $\operatorname{Mix}(6: 4)$ & 22.0 & 1.6 & 28.0 & 2.7 \\
\hline
\end{tabular}

TABLE II

ORDER INFORMATION

\begin{tabular}{|c|c|c|c|}
\hline $\begin{array}{c}\text { Order } \\
\text { No. }\end{array}$ & $\begin{array}{c}\text { Product } \\
\text { type }\end{array}$ & $\begin{array}{c}\text { Order size } \\
\text { (lot) }\end{array}$ & $\begin{array}{c}\text { Planned } \\
\text { release } \\
\text { date }\end{array}$ \\
\hline 1 & L & 6 & 3 \\
\hline 2 & M & 6 & 2 \\
\hline
\end{tabular}

and $L: M=6: 4$, respectively. The target on-time-delivery rate is set to $95 \%$.

In the situation where the product mix is $L: M=4: 6$ throughout the planning horizon, due dates need to be assigned to these two orders. Table II displays the information of the orders. Since the 95-percentile of gamma(25.0,2.0) is 67.5 and the 95-percentile of gamma(26.0, 2.3) is 80.31 , based on (6), the due dates of order 1 and order 2 (in days) can be obtained as

$$
\begin{aligned}
& D_{1}=3+120 / 24+67.5 / 24=10.8 \\
& D_{2}=2+145 / 24+80.31 / 24=11.39 .
\end{aligned}
$$

We note that the solution will be different when the product mix is $L: M=6: 4$ throughout the planning horizon. The 95 -percentile of gamma $(22.0,1.6)$ is 48.38 . The 95 -percentile of gamma(28.0, 2.7) is 100.53 . The due dates of order 1 and order 2 (in days) become 10.02 and 12.23 , respectively.

\section{Due-Date AssignMent For Periodical PRODUCT MiX CHANGES}

To tackle the effect of periodic changes on product mix, a contamination model is built for estimating waiting time (WT) of each product type. A due-date assignment model is then developed, by which the probability of a job being delivered on-time can be controlled.

\section{A. Contamination Model}

The contamination model, a mixture of distributions, provides a rich class of distributions that can be used in modeling data from a population that is composed of several homogeneous subpopulations. The contamination model is useful, particularly for cases with multiple manufacturing processes where the equipment or workmanship are not identical, or for cases where there are variable lead-time demands in the inventory management function. Such situations often result in production with inconsistent precision in production performance, and the contamination model should be used to characterize the population.

Let the observations $x_{1}, \ldots, x_{n}$ be a random sample from a contamination model with density function

$$
f(x)=\sum_{k=1}^{m} p_{k} \phi_{X}\left(\theta_{k}\right)
$$

where $\phi_{X}\left(\theta_{k}\right)$ is the density of $X$ in the $k$ th subpopulation distribution having parameter $\theta_{k}$, and $p_{k}$ is the probability of belonging to the $k$ th subpopulation. Thus, $0 \leq p_{k} \leq 1$ and $\sum_{k=1}^{m} p_{k}=1$.

Consider the contamination model of three gamma populations, with probability $p_{1}$ for population I distributed as $\operatorname{gamma}\left(\alpha_{1}=1, \beta_{1}=1\right)$, probability $p_{2}$ for population II distributed as gamma $\left(\alpha_{2}=2, \beta_{2}=1\right)$, and probability $p_{3}$ for population III distributed as gamma $\left(\alpha_{3}=3, \beta_{3}=1\right)$. The probability density function of the contamination gamma distributions may be expressed as

$$
f(x)=p_{1}\left[\phi_{X}\left(\alpha_{1}, \beta_{1}\right)\right]+p_{2}\left[\phi_{X}\left(\alpha_{2}, \beta_{2}\right)\right]+p_{3}\left[\phi_{X}\left(\alpha_{3}, \beta_{3}\right)\right]
$$

where $0 \leq p_{1} \leq 1,0 \leq p_{2} \leq 1,0 \leq p_{3} \leq 1, p_{1}+p_{2}+p_{3}=1$, and

$$
\phi_{X}\left(\alpha_{k}, \beta_{k}\right)= \begin{cases}\frac{x^{\alpha_{k}-1} e^{-x / \beta_{k}}}{\beta_{k}^{\alpha_{k}} \Gamma\left(\alpha_{k}\right)}, & x>0, k=1,2,3 . \\ 0, & \text { otherwise }\end{cases}
$$

In this contamination model, if $p_{1}=1$, then the contamination gamma model reduces to the distribution gamma $\left(\alpha_{1}, \beta_{1}\right)$. 


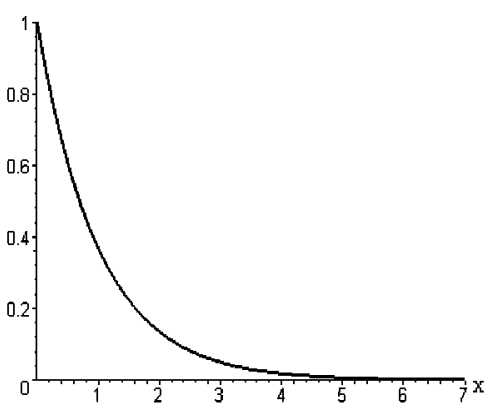

(a)

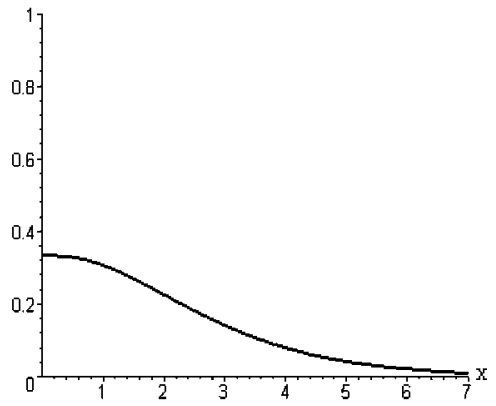

(d)

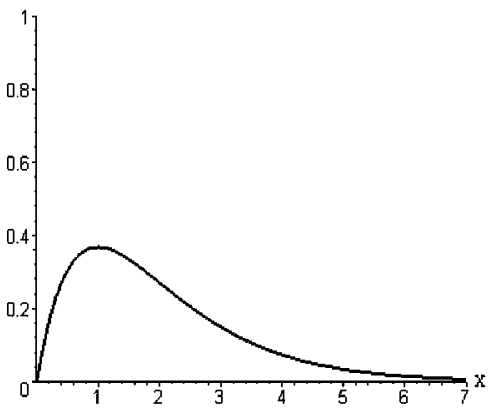

(b)

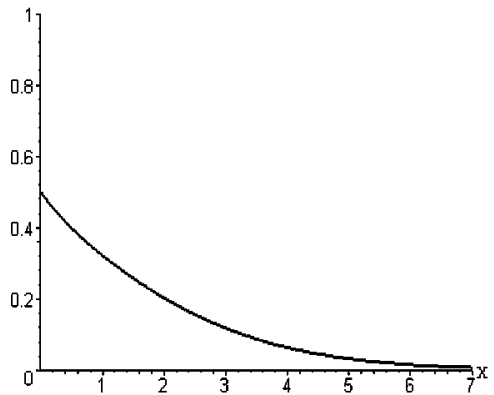

(e)

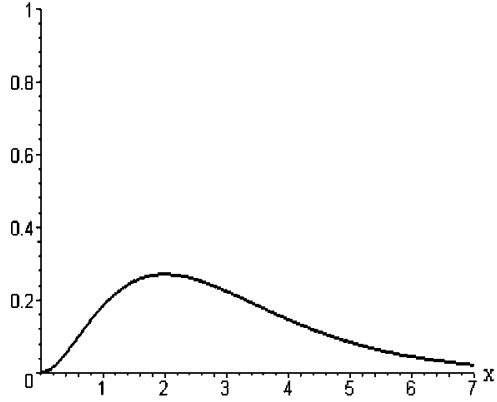

(c)

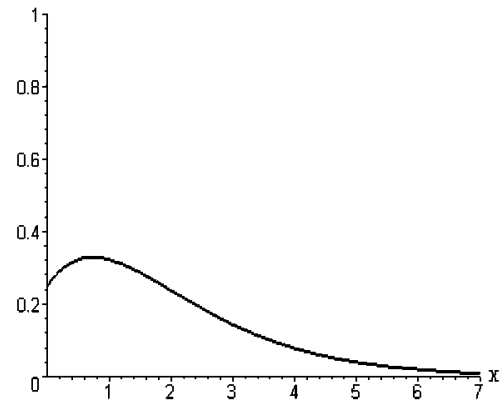

(f)

Fig. 3. Example of contamination model of three gamma distributions with different combinations of $p_{1}, p_{2}$, and $p_{3}$. (a) $p_{1}=1, p_{2}=0, p_{3}=0$. (b) $p_{1}=0$, $p_{2}=1, p_{3}=0$. (c) $p_{1}=0, p_{2}=0, p_{3}=1$. (d) $p_{1}=1 / 3, p_{2}=1 / 3, p_{3}=1 / 3$. (e) $p_{1}=1 / 2, p_{2}=1 / 4, p_{3}=1 / 4$. (f) $p_{1}=1 / 4, p_{2}=1 / 2, p_{3}=1 / 4$.

If $p_{2}=1$, then the contamination model reduces to the distribution gamma $\left(\alpha_{2}, \beta_{2}\right)$. On the other hand, if $p_{3}=1$, then the contamination model reduces to the distribution gamma $\left(\alpha_{3}, \beta_{3}\right)$. Fig. 3 displays various distributions modeled by the contamination of three gamma distributions gamma(1,1), gamma $(2,1)$, and gamma $(3,1)$ with six different combinations of $p_{1}, p_{2}$, and $p_{3}$. We note that the shape of the density differs for the different combinations of $p_{1}, p_{2}$, and $p_{3}$.

\section{B. Contamination Model for Periodic Product Mix Changes}

In wafer fabrication, the job release time and job completion time may not belong to the same time period due to the long flow time. Flow time of each job thus may be affected by the product mix settings in successive periods. When estimating the flow time of each job, the number of time periods for a job being processed in the plant should be taken into account for determining the number of components in a contamination model. The number of weeks required for determining the number of components in a contamination model is depending on the type of applications. In the fab we study, the simulation output turns out to be three weeks. Thus, the model of the contamination of three distributions is appropriate for this application. The probability $p_{\mathrm{t}}$ can be set to 1 divided by numbers of distributions. In the case of releasing job any day during week, the model can be refined by considering each single day.

The contamination model for WT of each product type may be expressed as

$$
f(x)=\sum_{t=1}^{N} p_{t}\left[\phi_{X}\left(\alpha_{t}, \beta_{t}\right)\right]
$$

where $t$ is index of time period, $N$ is the number of components in a contamination model, $0 \leq p_{\mathrm{t}} \leq 1, \sum_{t=1}^{N} p_{t}=1$, and

$$
\phi_{X}\left(\alpha_{t}, \beta_{t}\right)=\left\{\begin{array}{ll}
\frac{x^{\alpha_{t}-1} e^{-x / \beta_{t}}}{\beta_{t}^{\alpha} \Gamma\left(\alpha_{t}\right)}, & x>0 \\
0, & \text { otherwise }
\end{array} .\right.
$$

\section{Due-Date Setting}

For periodic product mix changes, the $\delta$-percentile waiting time is determined by the fitted contamination model in order to incorporate the effect of product mix changes. The due date of order $d$ can be assigned as

$$
D_{d}=r_{d}+P T_{d}+F C_{d}^{-1}(\delta)
$$

where $D_{d}$ is the due date of order $d, r_{d}$ is the release date of the latest batch of order $d, P T_{d}$ is PT of order $d$, and $F C_{d}^{-1}(\delta)$ is the inverse of the cumulative function of the fitted contamination distribution of order $d$. We note that when the product mix is fixed throughout the time periods, the results obtained by (6) and (14) are identical.

Consider the due-date assignment example described in Section III-B with two products $L$ and $M$. In the situation that the product mix is $L: M=4: 6$ in week 1 and $L: M=6: 4$ in week 2 , the probability density function of the WT contamination model for order 1 can be expressed as

$$
f_{1}(x)=\frac{1}{2} \times \frac{x^{25-1} e^{-x / 2}}{2^{25} \Gamma(25)}+\frac{1}{2} \times \frac{x^{22-1} e^{-x / 1.6}}{1.6^{22} \Gamma(22)} .
$$


TABLE III

SimUlation INPUTS FOR EACH PRODUCT Mix

\begin{tabular}{|c|c|c|c|c|c|c|c|}
\hline & \multirow{2}{*}{$\begin{array}{c}\text { Product mix } \\
\text { (A:B:C:D:E) }\end{array}$} & $\begin{array}{c}\text { Weekly } \\
\text { throughput } \\
\text { target (lot) }\end{array}$ & \multicolumn{4}{|c|}{ Mean flow time estimated by BBCT algorithm (hour) } & \multirow{2}{*}{ WIP level } \\
\cline { 3 - 7 } & & Product A & Product B & Product C & Product D & Product E & (lot) \\
\hline Mix(8:3:3:3:3) & 167 & 278.19 & 302.18 & 282.50 & 322.23 & 316.29 & 293 \\
\hline $\operatorname{Mix(6:6:2:5:1)~}$ & 163 & 280.80 & 305.73 & 282.63 & 322.40 & 316.43 & 292 \\
\hline $\operatorname{Mix}(6: 6: 2: 2: 4)$ & 164 & 281.02 & 306.01 & 282.71 & 322.32 & 316.44 & 292 \\
\hline $\operatorname{Mix}(5: 6: 4: 4: 1)$ & 165 & 279.47 & 303.98 & 282.61 & 322.25 & 316.33 & 292 \\
\hline $\operatorname{Mix}(5: 5: 5: 3: 2)$ & 166 & 277.79 & 301.71 & 282.47 & 322.08 & 316.17 & 293 \\
\hline $\operatorname{Mix}(5: 5: 5: 1: 4)$ & 167 & 277.91 & 301.86 & 282.53 & 322.04 & 316.18 & 293 \\
\hline $\operatorname{Mix}(3: 6: 5: 2: 4)$ & 165 & 276.58 & 300.29 & 282.13 & 321.74 & 315.83 & 292 \\
\hline
\end{tabular}

TABLE IV

Average AND Variance of WT COLleCted From SimUlation

\begin{tabular}{|c|c|c|c|c|c|c|c|c|c|c|}
\hline \multirow{2}{*}{$\begin{array}{c}\text { Product mix } \\
\text { (A:B:C:D:E) }\end{array}$} & \multicolumn{2}{|c|}{ Product A } & \multicolumn{2}{c|}{ Product B } & \multicolumn{2}{c|}{ Product C } & \multicolumn{2}{c|}{ Product D } & \multicolumn{2}{c|}{ Product E } \\
\cline { 2 - 12 } & $\bar{x}$ & $S^{2}$ & $\bar{x}$ & $S^{2}$ & $\bar{x}$ & $S^{2}$ & $\bar{x}$ & $S^{2}$ & $\bar{x}$ & $S^{2}$ \\
\hline $\operatorname{Mix}(8: 3: 3: 3: 3)$ & 92.08 & 304.88 & 107.61 & 677.82 & 86.66 & 298.90 & 106.22 & 402.96 & 101.29 & 390.75 \\
\hline $\operatorname{Mix}(6: 6: 2: 5: 1)$ & 95.31 & 333.81 & 102.15 & 350.29 & 86.49 & 329.24 & 104.58 & 332.60 & 98.91 & 201.26 \\
\hline $\operatorname{Mix}(6: 6: 2: 2: 4)$ & 95.49 & 383.99 & 101.66 & 312.21 & 87.55 & 339.96 & 103.32 & 491.26 & 99.03 & 291.70 \\
\hline $\operatorname{Mix}(5: 6: 4: 4: 1)$ & 97.26 & 409.32 & 100.85 & 327.00 & 89.98 & 451.71 & 103.31 & 370.68 & 97.51 & 217.46 \\
\hline $\operatorname{Mix}(5: 5: 5: 3: 2)$ & 95.15 & 344.06 & 103.18 & 400.89 & 87.00 & 244.98 & 106.11 & 414.07 & 102.25 & 533.36 \\
\hline $\operatorname{Mix}(5: 5: 5: 1: 4)$ & 95.80 & 404.42 & 102.35 & 411.94 & 88.23 & 307.18 & 100.91 & 184.76 & 100.74 & 339.70 \\
\hline $\operatorname{Mix}(3: 6: 5: 2: 4)$ & 102.27 & 984.04 & 99.84 & 390.44 & 87.12 & 302.58 & 105.82 & 581.61 & 99.55 & 369.08 \\
\hline
\end{tabular}

The probability density function of the WT contamination model for order 2 can be expressed as

$$
f_{2}(x)=\frac{1}{2} \times \frac{x^{26-1} e^{-x / 2.3}}{2.3^{26} \Gamma(26)}+\frac{1}{2} \times \frac{x^{28-1} e^{-x / 2.7}}{2.7^{28} \Gamma(28)} .
$$

The 95-percentile of WT distribution of orders can be obtained by taking the inverse of the cumulative fitted contamination function. Based on (15), the 95-percentile of WT of order 1 is 63.23. Based on (16), the 95 -percentile of WT of order 2 is 94.83. According to (14), the due dates of order 1 and order 2 (in days) can be solved as 10.63 and 11.99 , respectively.

\section{Simulation VerificATIONS}

To demonstrate the applicability of the due-date assignment model in real situations, we consider the example taken from a wafer fabrication factory located in the Science-based Industrial Park, Hsinchu, Taiwan.

\section{A. Simulation Environment}

The fab consists of 83 workstations (w1 to w83) and each workstation consists of a given number of identical machines operated in parallel. W46, a stepper in the photolithography area, is the bottleneck. The planned utilization rate of bottleneck machine is set to $90 \%$ in this study. The distribution of mean time between failures (MTBF), mean time to repair (MTTR), mean time between preventive maintenance (MTBPM), and mean time to preventive maintenance (MTTPM) for each workstation are known.

Five types of products are produced. A and B are the consumer logic products, while $\mathrm{C}, \mathrm{D}$, and $\mathrm{E}$ are the low-density SRAM products. Each product contains the numbers of circuit layers in a range of 17 to 20 . All product types have different process routes and each process route contains process steps in a range of 276 to 338 . PT for each product is as follows: 186.8 $\mathrm{h}$ for product $\mathrm{A}, 201.8 \mathrm{~h}$ for product $\mathrm{B}, 187.12 \mathrm{~h}$ for product $\mathrm{C}$, $216.23 \mathrm{~h}$ for product $\mathrm{D}$, and $211.78 \mathrm{~h}$ for product $\mathrm{E}$.

Based on CONWIP release policy, for each specific product mix, the planned WIP level, $L$ is set by using Little's law [31], $L=\lambda \times W$, where $\lambda$ is the average releasing rate and $W$ is the mean flow time. In this system, the average releasing rate $\lambda$ is equal to the throughput rate because CONWIP is adopted and mean flow time of each product is estimated by the block-based cycle time estimation algorithm (BBCT) [25].

Based on the system capacity limitation and market demand, seven product mixes are selected. For each product mix, simulation is run to collect PT and WT. The simulation program used in this paper is eM-Plant [32]. Based on the pilot runs, for getting a steady-state result, the simulation length is set to 448 days, in which the first 224 days are the warm-up period. In order to eliminate simulation errors, ten replications with different random seeds are run to get adequate statistical results under each product mix. The input data for each product mix is shown in Table III and the average $(\bar{x})$ and variance $\left(S^{2}\right)$ of the collected WT of each product type from running simulation for each product mix are shown in Table IV. 
TABLE V

ESTIMATED PARAMETERS FOR FITTED GAMMA DISTRIBUTIONS FOR WT

\begin{tabular}{|c|c|c|c|c|c|c|c|r|r|r|}
\hline \multirow{2}{*}{$\begin{array}{c}\text { Product mix } \\
\text { (A:B:C:D:E) }\end{array}$} & \multicolumn{2}{|c|}{ Product A } & \multicolumn{2}{c|}{ Product B } & \multicolumn{2}{c|}{ Product C } & \multicolumn{2}{c|}{ Product D } & \multicolumn{2}{c|}{ Product E } \\
\cline { 2 - 13 } & $\hat{\alpha}$ & $\hat{\beta}$ & $\hat{\alpha}$ & $\hat{\beta}$ & $\hat{\alpha}$ & $\hat{\beta}$ & $\hat{\alpha}$ & $\hat{\beta}$ & $\hat{\alpha}$ & $\hat{\beta}$ \\
\hline $\operatorname{Mix}(8: 3: 3: 3: 3)$ & 27.81 & 3.31 & 17.08 & 6.30 & 25.13 & 3.45 & 28.00 & 3.79 & 26.26 & 3.86 \\
\hline $\operatorname{Mix}(6: 6: 2: 5: 1)$ & 27.21 & 3.50 & 29.79 & 3.43 & 22.72 & 3.81 & 32.89 & 3.18 & 48.61 & 2.03 \\
\hline $\operatorname{Mix}(6: 6: 2: 2: 4)$ & 23.74 & 4.02 & 33.10 & 3.07 & 22.55 & 3.88 & 21.73 & 4.76 & 33.62 & 2.95 \\
\hline $\operatorname{Mix}(5: 6: 4: 4: 1)$ & 23.11 & 4.21 & 31.10 & 3.24 & 17.92 & 5.02 & 28.79 & 3.59 & 43.73 & 2.23 \\
\hline $\operatorname{Mix}(5: 5: 5: 3: 2)$ & 26.31 & 3.61 & 26.56 & 3.89 & 30.89 & 2.82 & 27.19 & 3.90 & 19.60 & 5.22 \\
\hline $\operatorname{Mix}(5: 5: 5: 1: 4)$ & 22.69 & 4.22 & 25.43 & 4.03 & 25.34 & 3.48 & 55.16 & 1.83 & 29.88 & 3.37 \\
\hline $\operatorname{Mix}(3: 6: 5: 2: 4)$ & 10.63 & 9.62 & 25.53 & 3.91 & 25.08 & 3.47 & 19.25 & 5.50 & 26.85 & 3.71 \\
\hline
\end{tabular}

TABLE VI

COMPARISON OF FITted GAMma Distribution AND Collected Data

\begin{tabular}{|c|c|c|c|c|c|c|c|c|c|c|}
\hline \multirow{2}{*}{$\begin{array}{c}\text { Product mix } \\
\text { (A:B:C:D:E) }\end{array}$} & \multicolumn{2}{|c|}{ Product A } & \multicolumn{2}{c|}{ Product B } & \multicolumn{2}{c|}{ Product C } & \multicolumn{2}{c|}{ Product D } & \multicolumn{2}{c|}{ Product E } \\
\cline { 2 - 11 } & $T_{95 \%}{ }^{*}$ & $\% * *$ & $T_{95 \%}$ & $\%$ & $T_{95 \%}$ & $\%$ & $T_{95 \%}$ & $\%$ & $T_{95 \%}$ & $\%$ \\
\hline $\operatorname{Mix}(8: 3: 3: 3: 3)$ & 122.52 & 96.52 & 153.70 & 94.12 & 116.97 & 95.23 & 141.12 & 95.79 & 135.94 & 96.82 \\
\hline $\operatorname{Mix}(6: 6: 2: 5: 1)$ & 127.22 & 96.28 & 134.75 & 95.17 & 118.34 & 96.38 & 136.28 & 96.62 & 123.34 & 96.15 \\
\hline $\operatorname{Mix}(6: 6: 2: 2: 4)$ & 129.84 & 96.65 & 132.36 & 96.02 & 119.92 & 95.43 & 142.27 & 95.51 & 128.69 & 95.16 \\
\hline $\operatorname{Mix}(5: 6: 4: 4: 1)$ & 132.75 & 95.96 & 132.32 & 96.75 & 127.55 & 96.07 & 136.88 & 96.04 & 122.97 & 95.07 \\
\hline $\operatorname{Mix}(5: 5: 5: 3: 2)$ & 127.57 & 95.38 & 138.17 & 96.21 & 114.24 & 96.47 & 141.65 & 95.55 & 142.97 & 96.39 \\
\hline $\operatorname{Mix}(5: 5: 5: 1: 4)$ & 131.10 & 95.56 & 137.86 & 95.64 & 118.90 & 96.99 & 124.26 & 95.98 & 132.85 & 95.55 \\
\hline $\operatorname{Mix}(3: 6: 5: 2: 4)$ & 158.73 & 94.18 & 134.41 & 96.98 & 116.76 & 95.68 & 148.36 & 95.09 & 133.11 & 95.82 \\
\hline
\end{tabular}

* $T_{95 \%}$ : theoretical 95-percentile WT of the fitted gamma distribution.

** \%: percentage of number of collected data $\leq T_{95 \%}$.

TABLE VII

Product Mix Composition For Five Product TyPes of EACH EXPERIMENT

\begin{tabular}{|c|c|c|c|}
\hline Experiment & Week 1 & Week 2 & Week 3 \\
\hline Experiment 1 & $\operatorname{Mix}(5: 5: 5: 3: 2)$ & $\operatorname{Mix}(5: 5: 5: 1: 4)$ & $\operatorname{Mix}(6: 6: 2: 5: 1)$ \\
\hline Experiment 2 & $\operatorname{Mix}(5: 6: 4: 4: 1)$ & $\operatorname{Mix}(6: 6: 2: 2: 4)$ & $\operatorname{Mix}(3: 6: 5: 2: 4)$ \\
\hline Experiment 3 & $\operatorname{Mix}(5: 5: 5: 1: 4)$ & $\operatorname{Mix}(8: 3: 3: 3: 3)$ & $\operatorname{Mix}(3: 6: 5: 2: 4)$ \\
\hline
\end{tabular}

\section{B. Data Distribution Fitting}

By using $\hat{\alpha}=\bar{x}^{2} / S^{2}$ and $\hat{\beta}=S^{2} / \bar{x}$, we estimate the parameters for gamma distributions fitted to WT of each product type under each product mix. The estimated parameters are listed in Table V. The theoretical 95-percentile WT of each fitted gamma distribution and the corresponding percentage of collected data are shown in Table VI. We see from Table VI that the gamma distribution appears to fit the collected WT satisfactorily.

\section{Periodical Product Mix Changes}

In this section, three experiments are used to demonstrate the effectiveness and accuracy of the due-date assignment model for the environment where the product mix changes periodically. For the experiments, product mix compositions for five product types are listed in Table VII.

Using the input data as displayed in Tables III and VII, the simulation model is run to collect WT of each product type for each piece of experiment.
TABLE VIII

PERFORMANCE SUMMARY FOR EXPERIMENTS

\begin{tabular}{|c|c|c|c|}
\hline Experiment & Product type & $\begin{array}{c}\text { 95-percentile flow time } \\
\text { (hours) }\end{array}$ & $\begin{array}{c}\text { On-time-delivery } \\
\text { rate }\end{array}$ \\
\hline \multirow{4}{*}{ Experiment 1 } & Product A & 315.45 & $96.75 \%$ \\
\cline { 2 - 4 } & Product B & 338.76 & $96.83 \%$ \\
\cline { 2 - 4 } & Product C & 304.33 & $94.79 \%$ \\
\cline { 2 - 4 } & Product D & 352.02 & $95.25 \%$ \\
\cline { 2 - 4 } & Product E & 345.63 & $95.42 \%$ \\
\hline & Product A & 328.53 & $97.12 \%$ \\
\cline { 2 - 4 } & Product B & 334.81 & $96.56 \%$ \\
\cline { 2 - 4 } & Product C & 309.04 & $97.37 \%$ \\
\cline { 2 - 4 } & Product D & 358.97 & $94.41 \%$ \\
\cline { 2 - 4 } & Product E & 340.40 & $96.71 \%$ \\
\hline \multirow{5}{*}{ Experiment 3 } & Product A & 326.69 & $97.39 \%$ \\
\cline { 2 - 4 } & Product B & 344.83 & $94.70 \%$ \\
\cline { 2 - 4 } & Product C & 304.89 & $96.78 \%$ \\
\cline { 2 - 4 } & Product D & 355.90 & $96.78 \%$ \\
\cline { 2 - 4 } & Product E & 345.79 & $96.68 \%$ \\
\hline
\end{tabular}

For each experiment, the contamination model for each product type can be derived from (12) and (13). The fitted contamination model and collected data distributions for experiments 1-3 are plotted in Figs. 4-6, respectively. The contamination model appears to fit the collected data well.

In this paper, the target on-time-delivery rate is set to $95 \%$. After deriving the contamination model, we can obtain the 


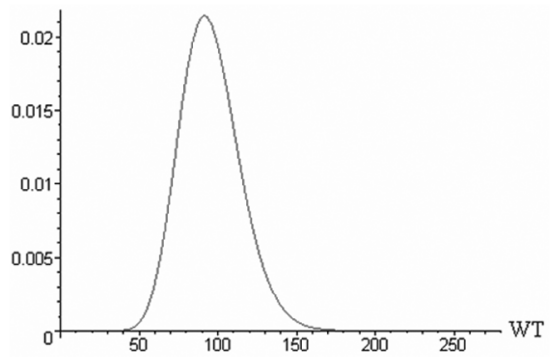

Fitted contamination model for Product A

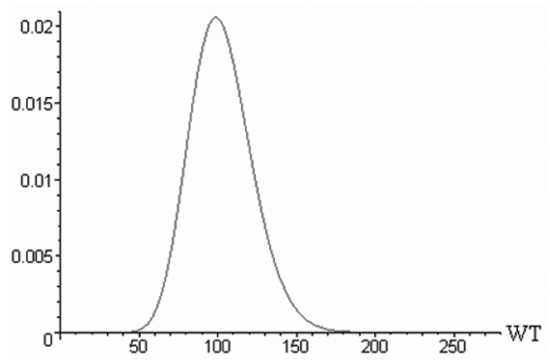

Fitted contamination model for Product B

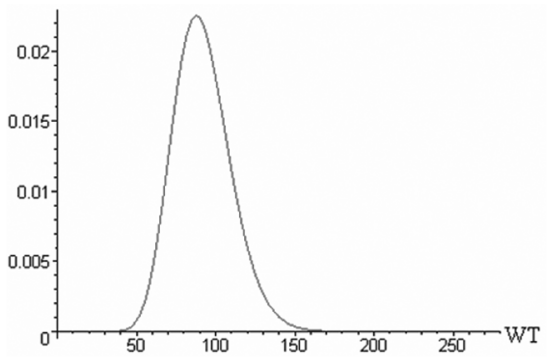

Fitted contamination model for Product C

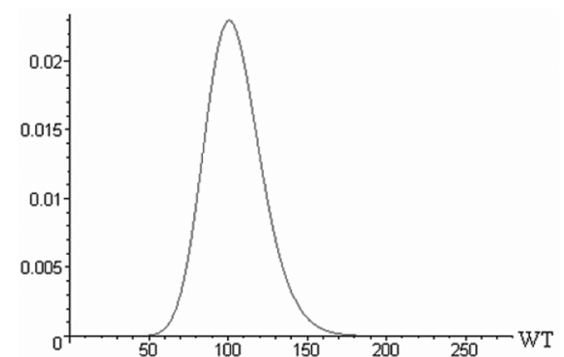

Fitted contamination model for Product D

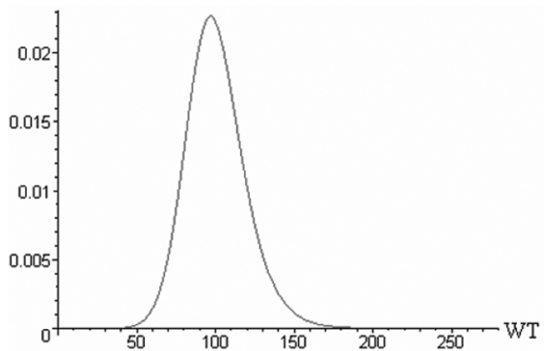

Fitted contamination model for Product E

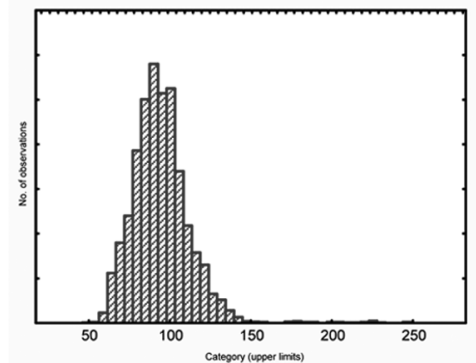

Histogram of the collected data for Product A

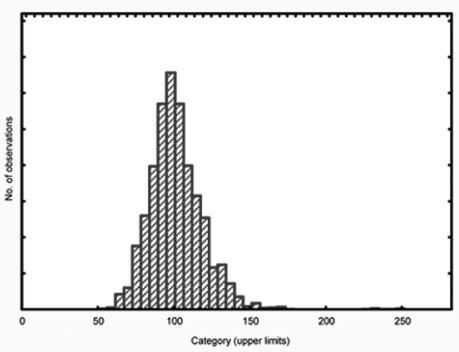

Histogram of the collected data for Product B

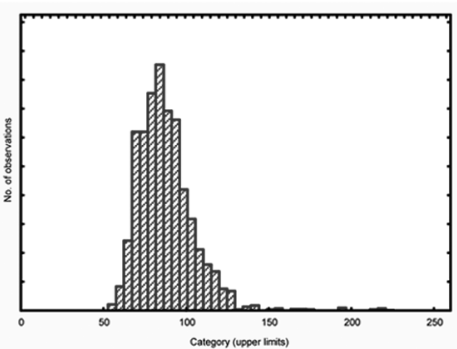

Histogram of the collected data for Product C

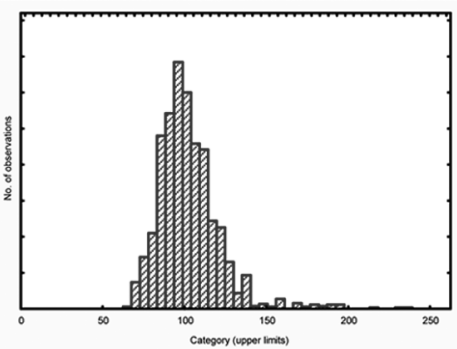

Histogram of the collected data for Product D

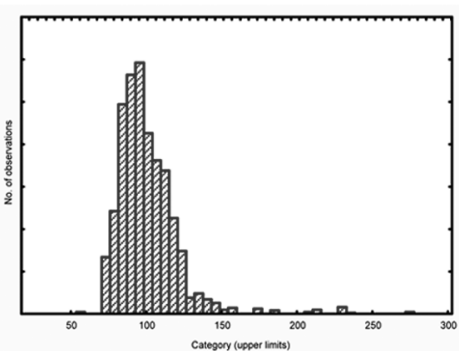

Histogram of the collected data for Product E

Fig. 4. Fitted contamination model versus histogram of collected data for experiment 1.

95-percentile flow time by summing up PT and 95-percentile WT by taking the reverse of the cumulative function of the contamination model. Table VIII displays the 95-percentile flow times and the on-time-delivery rate from the simulation 


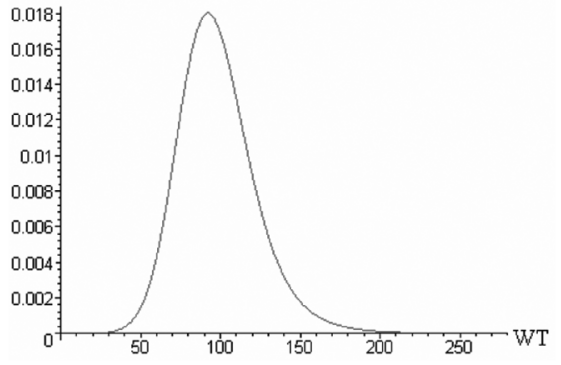

Fitted contamination model for Product A

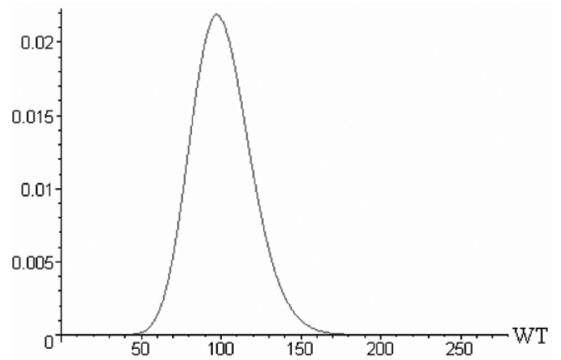

Fitted contamination model for Product B

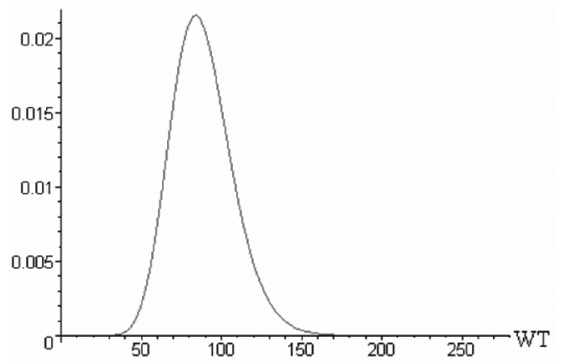

Fitted contamination model for Product C

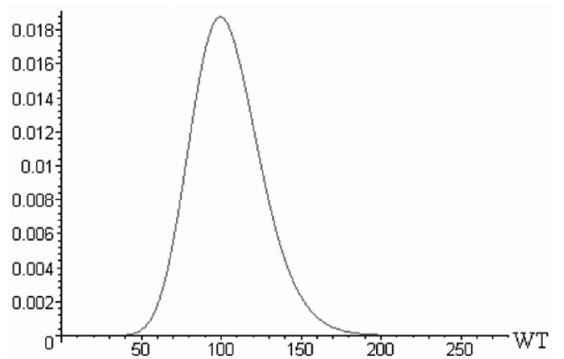

Fitted contamination model for Product D

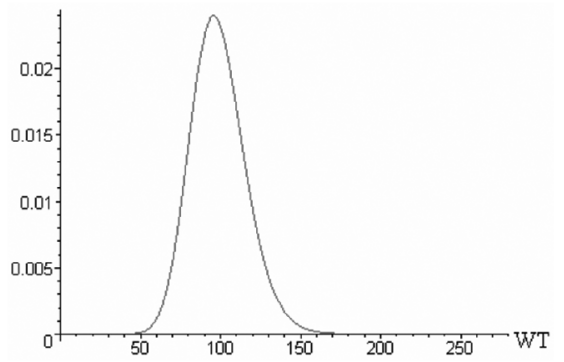

Fitted contamination model for Product E

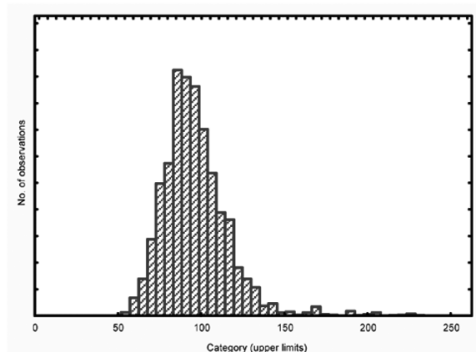

Histogram of the collected data for Product A

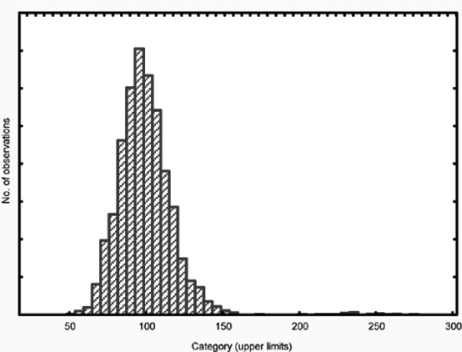

Histogram of the collected data for Product B

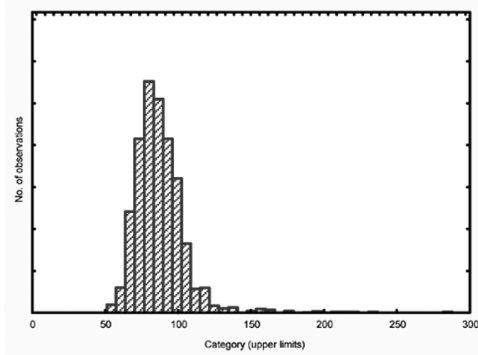

Histogram of the collected data for Product C

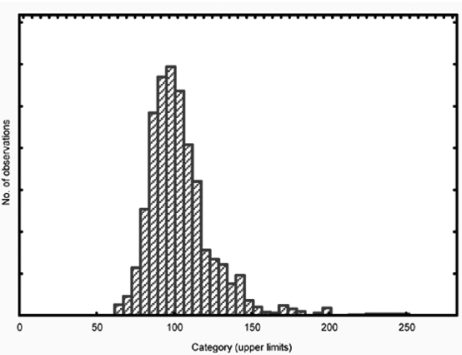

Histogram of the collected data for Product D

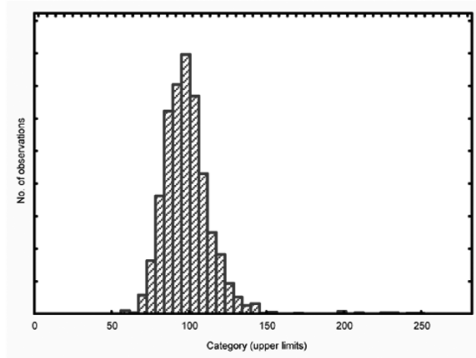

Histogram of the collected data for Product E

Fig. 5. Fitted contamination model versus histogram of collected data for experiment 2 .

data. As shown in Table VIII, the due-date assignment model by using contamination model performs well where the product mix changes periodically. As a result, the due-date assignment model provides quite a good solution. 


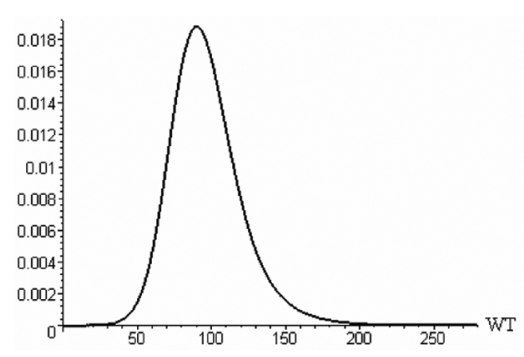

Fitted contamination model for Product A

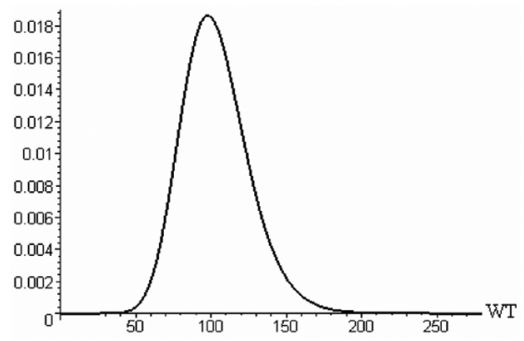

Fitted contamination model for Product B

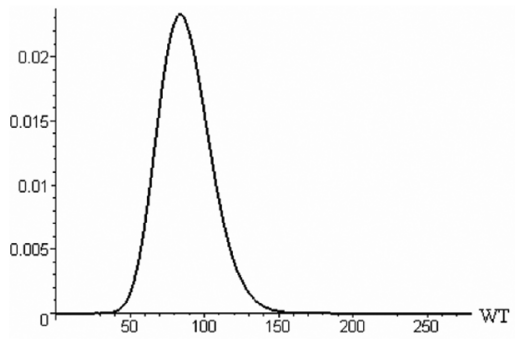

Fitted contamination model for Product C

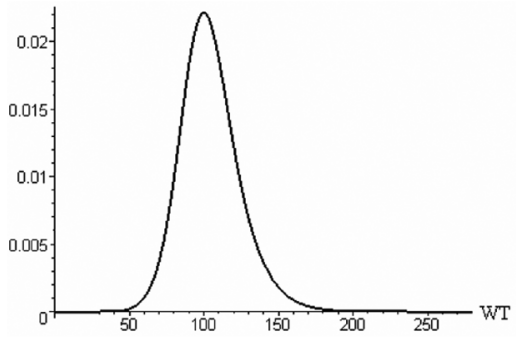

Fitted contamination model for Product D

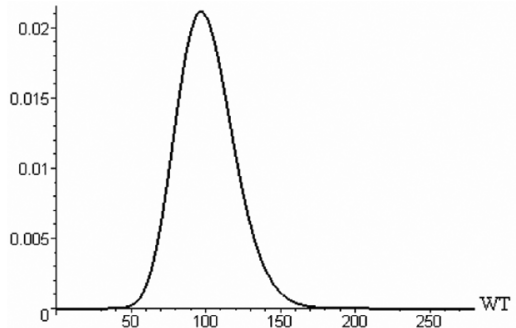

Fitted contamination model for Product E

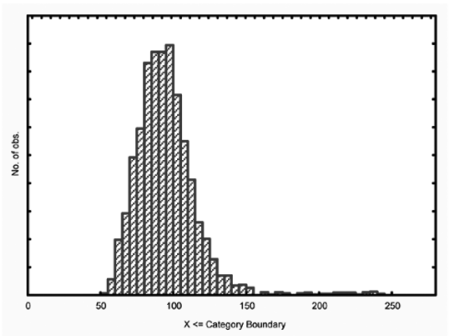

Histogram of the collected data for Product A

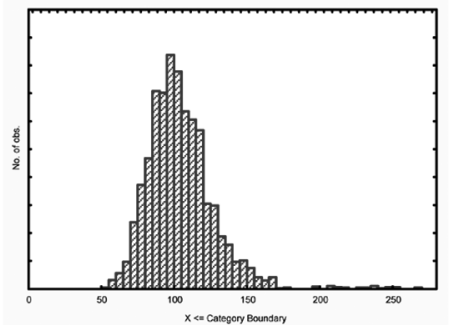

Histogram of the collected data for Product B

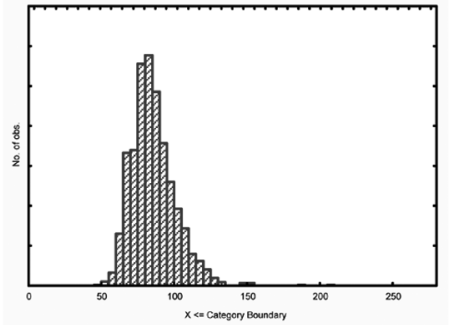

Histogram of the collected data for Product C

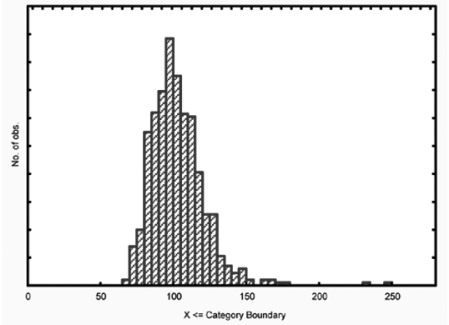

Histogram of the collected data for Product D

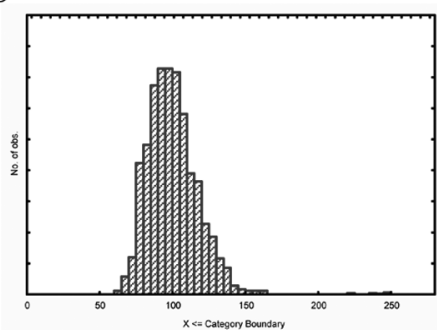

Histogram of the collected data for Product E

Fig. 6. Fitted contamination model versus histogram of collected data for experiment 3.

VI. CONCLUSION

In this paper, we considered the due-date assignment problem for wafer fabrication, an extension of the due-date assignment problem considered by Chung et al. [1], which has many real-world applications. We modeled the due-date assignment problem for wafer fabrication under two environments. For one 
with a single product mix, the waiting time of each product type is modeled by gamma distribution and the due dates are set to be consistent with the target on-time-delivery rate. The other is where the product mix changes periodically, the contamination model is applied to tackle the effects of product mix changes and the due dates can then be set. We also provided a real-world example taken from a wafer fabrication factory to demonstrate the effectiveness and accuracy of the proposed model. The results show that the due-date assignment model provides a quite good solution.

\section{REFERENCES}

[1] S. H. Chung, M. H. Yang, and C. M. Cheng, "The design of due date assignment model and the determination of flow time control parameters for the wafer fabrication factories," IEEE Trans. Compon. Packag. Technol, vol. 20, no. 4, pp. 278-287, Dec. 1997.

[2] T. C. E. Cheng and M. Gupta, "Survey of scheduling research involving due date determination decisions," Eur. J. Oper. Res., vol. 38, pp. 156-164, 1989.

[3] V. Gordon, J. M. Proth, and C. Chu, "A survey of the state-of-the-art of common due date assignment and scheduling research," Eur. J. Oper. Res., vol. 139, pp. 1-25, 2002a.

[4] — - "Due date assignment and scheduling: SLK, TWK, and other due date assignment models," Prod. Plan. Contr., vol. 13, no. 2, pp. $117-132,2002 b$.

[5] A. Seidmann and M. L. Smith, "Due date assignment for production systems," Manage. Sci., vol. 27, no. 5, pp. 571-581, 1981.

[6] T. C. E. Cheng, "Optimal due-date assignment in an assembly shop," Int. J. Oper. Prod., vol. 14, no. 2, pp. 31-42, 1994.

[7] S. T. Enns, "An economic approach to job shop performance analysis," Int. J. Prod. Econ., vol. 38, pp. 117-131, 1995.

[8] C. L. Li and T. C. E. Cheng, "Due-date determination with resequencing," IIE Trans., vol. 31, pp. 183-188, 1999.

[9] W. J. Hopp and M. L. Roofsturgis, "Quoting manufacturing due dates subject to a service level constraint," IIE Trans., vol. 32, pp. 771-784, 2000.

[10] H. P. G. Ooijen and J. W. M. Bertrand, "Economic due-date setting in job-shops based on routing and workload dependent flow time distribution functions," Int. J. Prod. Econ., vol. 74, pp. 261-268, 2001.

[11] A. C. Kaplan and A. T. Unal, "A probabilistic cost-based due date assignment model for job shops," Int. J. Prod. Res., vol. 31, no. 12, pp. 2817-2834, 1993.

[12] S. R. Lawrence, "Estimating flowtimes and setting due-dates in complex production systems," IIE Trans., vol. 27, pp. 657-668, 1995.

[13] S. T. Enns, "Lead time selection and the behavior of work flow in job shops," Eur. J. Oper. Res., vol. 109, pp. 122-136, 1998.

[14] J. K. Weeks and J. S. Fryer, "A methodology for assigning minimum cost due-dates," Manage. Sci., vol. 23, no. 8, pp. 872-881, 1977.

[15] I. Ahmed and W. W. Fisher, "Due date assignment, job order release, and sequencing interaction in job shop scheduling," Decis. Sci., vol. 23, no. 3, pp. 633-647, 1992.

[16] F. C. R. Chang, "A study of factors affecting due-date predictability in a simulated dynamic job shop," J. Manuf. Syst., vol. 13, no. 6, pp. 393-400, 1994.

[17] J. K. Weeks, "A simulation study of predictable due-dates," Manage. Sci., vol. 25, no. 4, pp. 363-373, 1979.

[18] M. M. Vig and K. J. Dooley, "Dynamic rules for due-date assignment," Int. J. Prod. Res., vol. 29, no. 7, pp. 1361-1377, 1991.

[19] _ - "Mixing static and dynamic flowtime estimates for due-date assignment," J. Oper. Manage., vol. 11, pp. 67-79, 1993.

[20] T. S. Raghu and C. Rajendran, "Due-date setting methodologies based on simulated annealing-An experimental study in a real-life job shop," Int. J. Prod. Res., vol. 33, no. 9, pp. 2535-2554, 1995.

[21] D. B. Roman and A. G. del Valle, "Dynamic assignment of due-dates in an assembly shop based in simulation," Int. J. Prod. Res., vol. 34, no. 6, pp. 1539-1554, 1996.

[22] F. C. R. Chang, "Heuristics for dynamic job shop scheduling with realtime updated queueing time estimates," Int. J. Prod. Res., vol. 35, no. 3, pp. 651-665, 1997.
[23] C. R. Glassey and S. Seshadri, "Transient flows in queueing systems via closure approximations," Queueing Syst., vol. 14, pp. 177-201, 1993.

[24] G. Riano, S. H. Ng, R. Serfozo, S. Hackman, and L. P. Chan, "Benchmarking of a stochastic production planning model in a simulation testbed," in Proc. Winter Simulation Conf., S. Chick, P. J. Sanchez, D. Ferrin, and D. J. Morrice, Eds., 2003, pp. 1183-1191.

[25] S. H. Chung and H. W. Huang, "The block-based cycle time estimation algorithm for wafer fabrication factories," Int. J. Indust. Eng., vol. 6, no. 4, pp. 307-316, 1999.

[26] Y. C. Chou and I. H. Hong, "A methodology for product mix planning in semiconductor foundry manufacturing," IEEE Trans. Semicond. Manuf., vol. 13, no. 3, pp. 278-285, Aug. 2000.

[27] M. A. Dümmler, "Analysis of the instationary behavior of a wafer fab during product mix changes," in Proc. Winter Simulation Conf., 2000, pp. $1436-1442$.

[28] S. J. Hood, S. Bermon, and F. Barahona, "Capacity planning under demand uncertainty of semiconductor manufacturing," IEEE Trans. Semicond. Manuf., vol. 16, no. 2, pp. 273-280, May 2003.

[29] M. L. Spearman, D. L. Woodruff, and W. J. Hopp, "CONWIP: A pul alternative to Kanban," Int. J. Prod. Res., vol. 28, pp. 879-894, 1990.

[30] R. V. Hogg and A. T. Craig, Introduction to Mathematical Statistics, 4th ed. New York: Macmillan, 1978.

[31] J. D. C. Little, "A proof for the queueing formula $L=\lambda W$," Oper. Res., vol. 9, pp. 383-387, 1961.

[32] Tecnomatix Technologies Ltd., eM-Plant Objects Manual Tecnomatix Software Company, Germany, 2000.

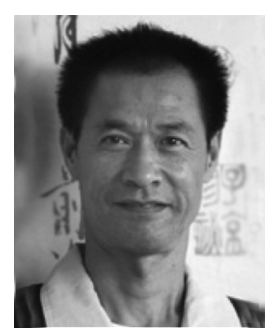

W. L. Pearn received the Ph.D. degree in operations research from the University of Maryland, College Park.

$\mathrm{He}$ is a Professor of operations research and quality assurance at National Chiao Tung University, Taiwan, R.O.C. He worked at AT\&T Bell Laboratories as a Quality Research Staff Member before joining National Chiao Tung University. His research interests include process capability, network optimization, and production management. His publications appeared in Journal of the Royal Statistical Society, Series C, Journal of Quality Technology, Journal of Applied Statistics, Statistics and Probability Letters, Quality and Quantity, Metrika, Statistics, Journal of the Operational Research Society, Operations Research Letters, Omega, Networks, International Journal of Productions Research, and others.

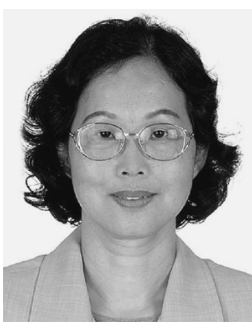

S. H. Chung received the Ph.D. degree in industrial engineering from Texas A\&M University, College Station, TX.

She is a Professor in the Department of Industrial Engineering and Management, National Chiao Tung University, Taiwan, R.O.C. Her research interests include production planning, scheduling, cycle time estimation, and performance evaluation. She has published and presented research papers in the areas of production planning and scheduling for IC manufacturing.

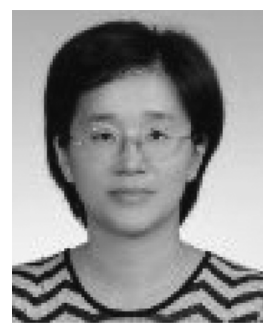

C. M. Lai is working toward the Ph.D. degree in the Department of Industrial Engineering and Management, National Chiao Tung University, Taiwan, R.O.C.

Her research interests include production planning, scheduling, and cycle time estimation. 